\title{
LOS DERECHOS FUNDAMENTALES Y LA CONSTITUCIÓN A LOS VEINTICINCO AÑOS
}

\author{
LORENZO MARTÍN-RETORTILLO BAQUER \\ Catedrático de Derecho administrativo \\ Universidad Complutense de Madrid
}

SUMARIO

INTRODUCCIÓN. PRIMERA PARTE: CÓMO LLEGAN LOS DERECHOS FUNDAMENTALES A LA CONSTITUCIÓN. SEGUNDA PARTE: QUÉ SE HIZO DE LOS DERECHOS FUNDAMENTALES TRAS LA CONSTITUCIÓN. 1. Ingente movilización del Legislador y de los Tribunales. 2. El creciente proceso de internacionalización. 3. Los derechos fundamentales y sus límites. 4. El ejercicio de un derecho no habilita para molestar a los demás. 5. Proyección de las opciones previstas. 6. La ampliación de los sujetos obligados. 7. Graduación de los derechos fundamentales. 8. La apuesta por el aprendizaje de los derechos fundamentales. FINAL.

\section{INTRODUCCIÓN}

La cifra de los veinticinco años es una buena ocasión para romper la rutina cotidiana y hacer tiempo para el recuerdo, la evocación y el contraste. Y dar aplicación a la vieja regla de que nada mejor para interpretar el presente y para preparar el futuro que esforzarse por conocer bien el pasado. De ahí el significado de recordar, pero recordar sin nostalgia, sin victimismo - virtud, al parecer, tan española ${ }^{1}-$, sin pasar

\footnotetext{
${ }^{1}$ Me impresiona la abundante presencia del victimismo en la actual sociedad española, muy frecuente entre los políticos, que han descubierto el ardid de inventar agresiones, que vienen de no se sabe donde, pero que caen bien a los oídos de sus electores, para así encubrir sus limitaciones o carencias cuando no para afianzar su poder. ¡Y es que la ignorancia es muy atrevida! Sobre todo, cuando se cuenta con al ignorancia del coro, encantado con tragar todo lo que le echen.
} 
factura ni demandar indemnización ${ }^{2}$. Por lo que importa no olvidar, tener presente lo que sucedió y cómo sucedió, dando así todo su significado al peso de la historia en las ciencias sociales y en el Derecho, en concreto. Entre otras cosas, por eso de que es verdad que el hombre suele tropezar dos veces en la misma piedra. Pero a su vez, esta operación de echar nuestra ojeada al pasado inmediato quiere tener también algo de incitación intelectual para hacer pensar y razonar sobre aspectos vitales de nuestra vida en sociedad.

La sugestiva problemática de los derechos fundamentales es un campo fértil al que hoy se dedica intensa atención ${ }^{3}$. La presente ocasión, con sus inherentes límites de tiempo y de espacio, fuerza necesariamente a acotar el campo y a seleccionar. Adoptaré por eso una visión dinámica, sintetizando ideas que he expuesto en otros lugares -de ahí la frecuencia de citas a anteriores trabajos míos-, centrándome en una ojeada de conjunto para destacar, en una primera parte, algo que hoy parecerá asumido y natural, pero que representó en su momento una importante selección y requirió notables esfuerzos: el por qué hay un título primero en la Constitución dedicado -aparte de a los deberes-, a los derechos fundamentales. Por su parte, el periodo de veinticinco años aludido ofrece perspectiva suficiente para reflexionar acerca de la dinámica y efectiva virtualidad de los derechos fundamentales y destacar algunas de las notas que juzgo más relevantes en su lógica proyección desde el texto constitucional hasta la realidad social y sus exigencias cotidianas, pensando sobre todo en los aspectos de técnica jurídica. Mucho tema, sin duda, para tan escaso tiempo, pero aún desde las limitaciones inherentes la empresa resulta sugestiva y atrayente.

\footnotetext{
2 De admirar, la elegancia de quienes hubieron de afrontar muy duras situaciones, soportando privaciones y sufrimientos, y una vez superados los tiempos críticos supieron organizar su vida sin estar haciendo gala de ello en la palestra pública, dando muestras de una entereza y calidad humana encomiables. Es decir, han sabido ser ejemplares tanto en la tormenta como cuando después llegó la bonanza.

${ }^{3}$ Desde que en 1988 apareció el pequeño libro que Ignacio DE OTTO Y PARDO y yo mismo dedicamos a Derechos fundamentales y Constitución (Cuadernos Cívitas), incluyendo sendos trabajos dedicados al régimen constitucional de los derechos y libertades, fruto de un grato encuentro entre constitucionalistas y administrativistas, que me agrada recordar -el volumen se abría con unas palabras de quien era entonces Presidente de la Asociación de Profesores de Derecho Administrativo, y que había propiciado dicho encuentro, profesor Sebastián Martín-Retortillo-, ha sido abundantísima la bibliografía dedicada a los numerosos aspectos que afectan a los derechos fundamentales. Me limitaré ahora a reseñar algunos títulos especialmente significativos, donde se hallarán las oportunas referencias bibliográficas a las que genéricamente me remito. A lo largo de la exposición iré aludiendo a algunos de mis trabajos donde he abordado con más detalle los aspectos que aquí se expondrán sucintamente y en los que también se encontrará la bibliografía correspondiente. Véase, en efecto, Antonio TRUYOL SERRA, Los derechos humanos. Declaraciones y convenios internacionales, con un amplio estudio preliminar, Ed. Tecnos, 2002; Juan Antonio CARRILlO SALCEDO, El Convenio Europeo de Derechos Humanos, Ed. Tecnos, 2003; Robert ALEXY, Teoría de los derechos fundamentales, Centro de Estudios Constitucionales, 1993.
} 


\section{PRIMERA PARTE: CÓMO LLEGAN LOS DERECHOS FUNDAMENTALES A LA CONSTITUCIÓN.}

Pongámonos en las aspiraciones de un significativo número de ciudadanos en el tramo final del anterior sistema político español, ciudadanos que pensaban, que tenían las antenas puestas, que podían así oír radios, que llegaban a conseguir libros y publicaciones, aunque hubiera que echar mano de tretas y argucias para ello, y que viajaban al extranjero, ya fuera como estudiantes -tengo siempre muy presente, en mi experiencia vital, en aquellos tiempos precisamente, el tan incitante periodo que tuve ocasión de vivir en la Universidad de Bolonia, en el Colegio de España-, como trabajadores o simplemente, y valga la redundancia, como viajeros curiosos. Pues bien, no pocos de esos españoles vivían con la ilusión de que se pudieran alcanzar en España un amplio conjunto de opciones sociales y fórmulas cívicas, que bien podían englobarse genéricamente bajo el rótulo de lo que llamamos los derechos fundamentales: el que fuera algo normal la existencia de partidos políticos, con todas sus implicaciones; o los sindicatos; la libertad de reunión y de manifestación; por supuesto, la libertad de pensamiento, de conciencia así como la de religión, con especial sensibilidad para que se superara el periodo en el que se imponía una religión oficial, que es lo que significaba en la practica la confesionalidad del Estado; la desaparición de la censura para la edición de libros y publicaciones y, en general, la libertad de expresión, incluida, obviamente, la libertad de prensa; la libre entrada y salida en y del territorio nacional, sin las pegas inherentes habitualmente al control de pasaportes; sin duda, la erradicación de los malos tratos y de cualquier variante de tortura; la abolición de la pena de muerte, y un muy largo etcétera. Pasos, todos ellos alcanzados y realizados, ¡cuesta trabajo imaginar que no existían!, pero tal era la situación con anterioridad a la Constitución cuyos veinticinco años celebramos.

Los españoles del periodo señalado no es que soñaran con invenciones o descubrimientos, sino que bien presentes estaban las tradiciones constitucionales, y las Constituciones de los países de nuestro entorno cultural eran inmejorable espejo en que mirarse. Se sabía lo que se quería, muy claro estaba a dónde quería llegarse y de dónde quería salirse. A nadie había que convencer de ello, al margen de los recalcitrantes, nostálgico o inmovilistas, que no faltaban. Muy lejos los tiempos y circunstancias en que hubo de surgir el famoso texto clásico que, por más que se repita siempre, no puedo dejar de citar en la presente ocasión: no valía la Constitución del Antiguo Régimen, vienen a decir quienes protagonizan inicialmente la Revolución Francesa, esas élites cultas burguesas, que hicieron la Declaración de Derechos del Hombre y del Ciudadano de 26 de agosto de 1789. Recuérdese, en cambio, que Martínez Marina, en la tesitura española de la Constitución gaditana de 1812, intentaría tratar de convencer, por el contrario, que lo que se iba a hacer era codificar la Constitución tradicional española: ¡ya estaba en la historia la fuente de las nuevas fórmulas! No, no fue tal la postura de quienes unos cuantos años antes, en la situación francesa citada, se pronunciaban tajantemente dejando bien claro en el artículo 16 de la Declaración de 1789 que:

“Toute societé, dans laquelle la garantie des droits n'est pas assurée, ni la séparation des pouvoirs determinée, n'a point de constitution ».

Que nadie se engañe, no hay realmente constitución si no se asume el compromiso de garantizar determinados valores. Que antes no estaban garantizados. De ahí, la 
necesidad de una innovación radical, de modo que, en concreto, por incidir en la doble dirección apuntada:

a) Necesidad de asumir unas reglas modernas y rompedoras en la distribución y separación de los poderes del Estado (lo cual hoy nos sigue pareciendo un postulado irrenunciable, sobre el que poco será lo que se insista, de forma que, según las características de nuestro tiempo, los poderes o los órganos del Estado tienen que ser consecuentes con sus funciones y prerrogativas pero también con sus limitaciones ${ }^{4}$ ).

b) Consagración inequívoca de unos valores, dándoles realce y presencia efectiva, codificando así un poso, cuya teorización había requerido esfuerzos ingentes y sobre los que tan de lleno había incidido la obra de la Ilustración. Recordaré, por traer sólo un ejemplo, el alcance de la magnífica construcción del Marqués de Beccaria, con la elaboración, entre otras cosas, del "nullum crimen", origen de un planteamiento sobre el principio de legalidad penal que hoy nos parece un patrimonio constitucional irrenunciable.

Conjunto de valores que se reducen y sintetizan, es decir, se codifican, bajo el rótulo expresivo de los derechos humanos. De forma que, sin ellos, no hay Constitución.

Pues bien, cuando hace veinticinco años se hizo la Constitución española, a nadie hubo que convencer de que había que llevar a cabo una operación similar. Era algo obvio y asumido el que entre las innovaciones auspiciadas, se contaba con la introducción de un paquete significativo de lo que se llamarían entonces los derechos fundamentales. Algo ausente en el anterior sistema y que era preciso incorporar sin falta, costara lo que costara. Alterando, innovando y derogando, por supuesto. Operación que, además, se apoyaba en una rica corriente, sensible no sólo en los países de nuestro entorno cultural, sino de indudable ámbito universal: la bandera de los derechos humanos era la más visible expresión del grito de nunca más que surge en la patética situación espiritual de la Europa de 1945, o más precisamente, del mundo, en la conmoción que produjo el testimonio de barbarie y salvajismo de la Segunda Guerra Mundial, con todas las circunstancias que condujeron a ella, incluida la prepotencia y crueldad del nazismo y demás regímenes totalitarios. Para que nunca más volviera a repetirse algo parecido se llega a la conclusión de que una de las fórmulas es el compromiso inexcusable por parte de los Estados de respeto a unos valores, concreción depurada de aspiraciones generalizadas, y que se aglutinan bajo el rótulo de los derechos humanos. No hay más que ver su peso y presencia en las Constituciones que surgirán entonces. Pero hay que contar, además, con otro fenómeno paralelo, o mejor, entrelazado con el anterior, que proviene del mismo origen, y que va a añadir enorme fuerza, cual es el fenómeno de la decidida internacionalización de los derechos humanos. Hitos de este último fenómeno serán documentos de tanto peso histórico $-\mathrm{y}$ quiero llamar especialmente la atención sobre su fecha- como la Carta de Naciones Unidad (San Francisco 1945), la Declaración Universal de Derechos Humanos (París $1948)^{5}$ o, por traer tan solo un nuevo ejemplo, el Convenio Europeo para la Protección

\footnotetext{
${ }^{4}$ Me remito a mi trabajo De la separación y control de los poderes en el sistema constitucional español, en mi libro Méritos o botín y otros retos jurídicos de la democracia, Aranzadi, 2000, 133 ss.

${ }^{5} \mathrm{Me}$ remito a mi trabajo, La efectiva aplicabilidad de la Declaración Universal de Derechos Humanos en el sistema jurídico español, "Revista de Administración Pública", 153 (2000), 41 ss .
} 
de los Derechos Humanos (Roma 1950) ${ }^{6}$ (citado en adelante como CEDH). Con esta línea se entrelazan y mezclan, en un estimulante fenómeno de interacción, las Constituciones, que son la respuesta expresa de los Estados más sensibilizados o afectados: la Francesa de 1946, la Italiana de 1948, la Ley Fundamental de Bonn de $1949 \ldots$

La imparable línea -tan positiva- de internacionalización de los derechos humanos va a incidir de forma directa en el fenómeno de la creciente interrelación de los ordenamientos jurídicos, un fenómeno sobresaliente en la configuración de los modernos sistemas jurídicos, y que resulta especialmente sensible en lo referente a los derechos fundamentales y las libertades públicas.

De entre los muchos pasos destacables que jalonaron ese brillante periodo de la historia de España que denominamos la "Transición Política", algunos de ellos, y bien significativos, tenían que ver con los derechos humanos: el ingreso en el Consejo de Europa, la firma del CEDH (el 24 de noviembre de 1977) ${ }^{7}$, la ratificación de los dos "Pactos de Nueva York", el de Derechos Civiles y Políticos y el de Derechos Económicos, Sociales y Culturales (el 13 de abril de 1977), y un largo etcétera.

Por fortuna, la fuerza de la corriente de revalorización de los derechos humanos, que tan pujante surgió nada más acabar la Segunda Guerra Mundial, ni decayó ni se debilitó. Es así como ambas tendencias dejaron sentir con fuerza su influjo cuando España estuvo en condiciones de volver a alinearse con los países de su entorno histórico y elaborar una Constitución democrática.

En efecto, al igual que en las Constituciones referidas, los derechos fundamentales van a ocupar un lugar muy destacado en la Constitución de 1978. Han contado los autores de la famosa "Ponencia Constitucional" - los bien conocidos siete diputados que redactaron el que sería texto de trabajo- cómo se barajó la hipótesis de resolver el problema de la presencia de los derechos fundamentales con una remisión al prestigioso y tan admirado Convenio Europeo para la Protección de los Derechos Humanos. Pero la fórmula no pareció suficiente a la vista de las expectativas levantadas, dadas, de una parte, las carencias manifiestas y, de otra, las aspiraciones reales en materia de derechos humanos. Es así como se llegaría al amplio contendido del Título Primero, reflejo de un esfuerzo considerable por dar cabida a una enumeración lo más extensa posible, en el que se reúnen, en efecto, valiosos y numerosos elementos, bien que de diversa funcionalidad:

- ante todo, los derechos fundamentales y libertades públicas, de la famosa sección primera del capítulo segundo, auténtico "sancta santorum" de los derechos ${ }^{8}$

\footnotetext{
${ }^{6}$ Véase mi libro, La Europa de los derechos humanos, Centro de Estudios Políticos y Constitucionales, Madrid 1998, 27 ss.

${ }^{7}$ La ratificación se llevaría a cabo, una vez promulgada la Constitución, en 1979, y sería en 1981 cuando, según la regulación entonces vigente, se haría la declaración necesaria para que pudiera producirse la "reclamación individual" por parte de los ciudadanos

${ }^{8}$ Me remito a mi trabajo, Eficacia y garantía de los derechos fundamentales, en mi libro, La Europa de los derechos humanos, cit., 67 ss.
} 
- en otro escalón, con algo menos de bríos, pero inequívocos, los derechos de los ciudadanos (de la sección segunda);

- intensa presencia igualmente, tercer escalón, de los principios rectores de la política social y económica, donde encajan muchos derechos sociales (capítulo tercero);

- de gran peso también, el mandato general de no discriminación y apoyo a la igualdad (art. 14);

- muy importante así mismo el papel reservado a la "cláusula de transformación", con el compromiso de remover los obstáculos que impidan o dificulten la libertad y la igualdad, que tiene cabida nada menos que en el Título preliminar (art. 9.2);

- referiré, por último, las minuciosas reglas para asegurar la garantía de los compromisos que acabo de enumerar, lo que nos lleva al artículo 53, precepto central, donde, entre otras cosas, aparece la importante regla, sobre la que quiero llamar la atención especialmente aquí y ahora, del "recurso efectivo": que ante cada violación de los derechos fundamentales pueda haber siempre una opción jurisdiccional, variante que luego se refuerza con la oportunidad del recurso de amparo ante el Tribunal Constitucional para los derechos más cualificados.

De una visión comparativa y global se deduce que para alcanzar todo lo anterior se tuvo muy en cuenta el panorama constitucional disponible, con el conocido efecto de que los documentos más recientes son los que han tenido oportunidad de incorporar mayor número de fórmulas. Grande fue el influjo, entre otras, de la Constitución Italiana y de la Alemana, señaladamente también el de la, entonces tan reciente, Constitución Portuguesa de 1976. Cuando hablo de la influencia constitucional quiero referirme también al ejemplo, decisivo, de los textos internacionales referidos, señaladamente el $\mathrm{CEDH}$, que como es bien sabido resulta ser un epítome de la Declaración Universal de Derechos Humanos. La cualificada regla del "recurso efectivo", que mencionaba, proviene del artículo 8 de este último texto y se perfilaría en el artículo $13 \mathrm{CEDH}$.

Pero no sólo ayudaron a moldear contenidos, he de destacar también la presencia en la Constitución de fórmulas expresas que tienen que ver muy directamente con ese fenómeno de la incidencia de lo supranacional y los mecanismos institucionales inherentes. Destacaré así dos notas.

a) La solución de la recepción del Derecho internacional que ha consagrado el artículo 96 -siguiendo la línea que luce en el artículo 1.6 del Código civil- es un cauce privilegiado para la interconexión de ordenamientos jurídicos, pues permite abrir la puerta para que, según su fórmula, pasen a convertirse en derecho interno, entre otros, documentos internacionales en materia de derechos humanos de gran trascendencia. Es así como, andando el tiempo, España firmaría y ratificaría instrumentos de gran peso referentes a los derechos fundamentales, ya fueran las "declaraciones de derechos" más

\footnotetext{
${ }^{9}$ Véase mi trabajo, Tres opciones jurisdiccionales para la defensa de los derechos fundamentales, en el Libro Homenaje al Profesor Rubio Llorente, Madrid, 2003.
} 
influyentes -se aludió antes al CEDH o a los Pactos de Nueva York-, ya una enorme cantidad de acuerdos, convenciones y convenios más específicos, en relación con actividades o grupos especialmente sensibles: esclavitud o trata de personas, tortura, discriminación racial o por el sexo, protección de menores, etc., etc.

b) No puedo por menos de aludir al papel tan destacado que desempeña el artículo 10.2, del que ya me he ocupado en otras ocasiones ${ }^{10}$, con su referencia a la Declaración Universal de Derechos Humanos, pero también acercando aún más al sistema constitucional español las grandes declaraciones de derechos, y que va a permitir así primar a la jurisprudencia del Tribunal Europeo de Derechos Humanos a la hora de la interpretación de nuestras reglas. Un precepto polémico en sus orígenes -luego no-, complejo y difícil, pero llamado a abrir muchas oportunidades.

En conclusión, que los derechos humanos penetran ostensiblemente en la Constitución Española pues, en su momento, era inconcebible una constitución que no les dedicara la mayor importancia. El panorama constitucional existente sirve de incentivo y ofrece sus modelos; pero también se reflejará el creciente proceso de internacionalización.

Dada la metodología que he elegido para esta intervención no tiene sentido que entremos ahora a estudiar ni siquiera a enumerar el amplio catálogo de derechos. Destacaré no obstante, no solo la consistencia y prestancia de los mismos, sino también la variedad de registros y la diversidad: desde las libertades más clásicas -como prensa (art. 20), reunión (art. 21), asociación (art. 22), etc.- hasta derechos de profundo significado social -como el derecho a la educación (art. 27), vivienda (art. 47) o negociación colectiva (art. 37.1)-, o derechos que son testimonio de aspiraciones bien recientes -como el derecho a la protección de la salud (art. 43), el derecho al medio ambiente (art. 45) o a la protección frente a los excesos de la informática (art. 18.3)-. Pero no hay sólo una enumeración cerrada. La relación codificada cuenta a su vez con los mecanismos jurídicos que facilitan y permiten la ampliación del caudal de derechos existente. Lo cual es también muy importante, sobre todo en un mundo dinámico como el nuestro, y donde no escasean las fuerzas agresivas, lo que reclama incesantemente la colocación de nuevos valores en el punto de mira para asegurar su protección.

\section{SEGUNDA PARTE: ¿QUÉ SE HIZO DE LOS DERECHOS FUNDAMENTALES?}

Hasta aquí la exposición de lo que se logró llevar al texto de la vigente Constitución cuando se hizo hace veinticinco años. En esta segunda parte pasamos a interrogarnos acerca de su dinámica aplicativa: ¿Cómo han funcionado las previsiones? ¿Qué nos ha deparado la experiencia? ¿En que ha venido a parar tan amplia proclamación? ¿Qué ha resultado especialmente relevante para los juristas al intentar dar cumplimiento a tan señalados compromisos? Es un tema largo de contar, muy rico

\footnotetext{
${ }^{10}$ Véase así mis trabajos, Notas para la historia del apartado segundo del artículo 10 de la Constitución de 1978, y La recepción por el Tribunal Constitucional de la jurisprudencia del Tribunal Europeo de Derechos Humanos, en mi libro, La Europa de los derechos humanos, cit., 177 ss. y 245 ss., respectivamente.
} 
en contenidos y también en problemas. Pero la cortesía académica me exige sintetizar, por lo que seleccionaré unos cuantos aspectos que a mi me parecen representativos y centraré mis reflexiones en torno a ocho puntos.

Primero. Se puede constatar, ante todo, que las exigencias constitucionales han provocado una ingente movilización para cumplir los compromisos que suponen los derechos fundamentales, ya de orden normativo (A), ya como protagonismo de quienes han sido llamados a su defensa (B), lo que se tradujo normalmente en actuaciones de corte judicial.

(A). La respuesta normativa ha sido, en efecto, muy abundante, dando lugar, a su vez, a textos de diferente significado y funcionalidad.

a). Habrá que fijarse, así, en la larga lista de leyes, ya abordando la regulación genérica de los derechos y libertades fundamentales, por lo que normalmente serán de las Cortes Generales y adoptarán la variante de leyes orgánicas, ya asumiendo la financiación de las actividades inherentes a los derechos, donde cabrá también una activa participación de las Comunidades Autónomas. De entre aquellas, por fijarme sólo en las más recientes, aludiré a las Leyes Orgánicas regulando el Derecho de Petición (L.O. 4/2001, de 12 de noviembre ${ }^{11}$ ), el Régimen Jurídico de las Asociaciones, o la tan actual referente al sistema de Partidos Políticos.

Pero a su vez, junto a la imprescindible tarea de fijar el marco jurídico para el ejercicio de los derechos, una intensa movilización de energía ha reclamado la atención parlamentaria en relación con la financiación de las actividades inherentes a los diversos derechos y libertades, considerada hoy faceta imprescindible ${ }^{12}$. Y aquí, insisto, ha sido muy activa la participación de las Comunidades Autónomas, cuyas Asambleas legislativas han multiplicado las respuestas. No hay mas que recordar las partidas tan consistentes destinadas, según los casos, ya por las Cortes Generales ya por las Asambleas autonómicas, a la financiación de los partidos políticos, de los sindicatos, de la Iglesia Católica y de otras organizaciones religiosas, de asociaciones, como las de consumidores o las deportivas, o al fomento de actividades como las culturales, de investigación, de protección del patrimonio histórico y folklórico, o de promoción de jóvenes, de la mujer, de minusválidos, etc., etc. Insisto que la movilización y la respuesta en todos estos campos ha sido ingente y ha representado, por ende la dedicación de cuantiosas energías, no siempre aparatosas o de escaparate, pero decisivas para el buen funcionamiento de los derechos y libertades y, en definitiva, para la mejora de la sociedad.

b) No menos intensa ha sido la respuesta del legislador que quiere defender los derechos fundamentales elaborando normas que desaconsejen conductas contrarias a los mismos, ya por medio de la tipificación de infracciones administrativas (por ejemplo, protección del derecho a la vida con las sanciones en materia de alimentos, de sanidad

\footnotetext{
${ }^{11}$ Vid., F. GONZÁLEZ NAVARRO y J.F. ALENZA GARCÍA, Derecho de petición. Comentarios a la Ley Orgánica 4/2001, de 12 de noviembre, Cívitas, Madrid, 2002.

12 Sobre la "normalidad" del soporte público, incluso prestacional, para la efectividad de los derechos, aún los de corte más liberal, en línea con las exigencias de la "cláusula de transformación" del art. 9.2, véase Lorenzo MARTÍN-RETORTILLO, Los derechos fundamentales como ámbito de libertad y compromiso de prestaciones, "Revista Aragonesa de Administración Pública”, núm. 15 (1999), 19 ss.
} 
animal o de tráfico, incluso), ya directamente a través del Código Penal, que ha sido objeto no sólo de la reelaboración de 1985 sino de numerosas reformas.

(B) Pero también en estos años se ha dado lugar a una intensísima práctica judicial, de forma que, por decirlo de una manera simple, como bien saben ustedes, los derechos fundamentales han dado mucho trabajo a los jueces. Y ello, desde distintas opciones o alternativas ya que la imaginación ha resultado fértil a la hora de habilitar cauces procesales.

a) Ante todo, y por referirme a los procedimientos específicos dejando ahora los cauces ordinarios, la vía judicial cualificada de protección de los derechos fundamentales, inicialmente a través de la Ley 62/1978, de 26 de diciembre, de Protección Jurisdiccional de los Derechos de la Persona, hoy, en el campo de lo contencioso-administrativo, el procedimiento especial de los artículos 114 y siguientes de la Ley jurisdiccional, versión de 1998.

b) Si la anterior ha dado mucho juego, una carretera muy transitada ha resultado ser la del recurso de amparo ante el Tribunal Constitucional, carretera holgada, pronto convertida en un enorme atasco, ahogada en su propio éxito, consecuencia lógica tanto del sistema, como de la creciente recurribilidad que se ha manifestado durante estos años, como de las facilidades e incitaciones que inicialmente dieron los jueces constitucionales.

c) No han sido tan abundantes como en otros países, ni siquiera muy interesantes en su mayoría, pero dan testimonio de otra alternativa eficaz, los casos encaminados al Tribunal Europeo de Derechos Humanos.

Y, d), en el otro camino antes señalado, no les ha faltado trabajo a los jueces de lo penal a la hora de sancionar las conductas contrarias a los derechos fundamentales.

Dos. Se habló del proceso de internacionalización como de algo asumido: no sólo no ha dejado de afianzarse y profundizarse, ha ido claramente a más, sin rodeos ni vacilación. Cada vez evidencia más intensidad, y no ha dejado de incrementarse el número de convenios que van proyectando protección a grupos o sectores necesitados de ella. Con lo que desempeña un papel muy eficaz como puerta abierta al futuro para que penetren nuevos derechos fundamentales, o para reforzar y proyectar los ya reconocidos, sin necesidad de llegar a la reforma constitucional. Insisto sobre esta oportunidad ampliatoria, de tanta trascendencia.

a) Se habló así del CEDH, de 1950, pero este no es un instrumento inmóvil o petrificado, sino que periódicamente se va completando a través de "protocolos adicionales". España ratificaría varios de ellos -no todos-, como el Número Uno ${ }^{13}$, cuyo artículo primero, de garantía del derecho de propiedad, ya estaría presente en la Constitución a través del artículo 33, pero en cambio, según el sistema interno, la propiedad no es un derecho susceptible del recurso de amparo y ahora sí puede llegar al Tribunal Europeo; el Número Seis, sobre abolición total de la pena de muerte; o,

\footnotetext{
${ }^{13}$ De 1952, firmado por España en 1978 y ratificado solo en 1990.
} 
recientemente, el referente a las aplicaciones de la biología y la medicina, que prohíbe la clonación de seres humanos, de 1998, que España ratificó en $2000^{14}$.

b) También resulta de especial interés en esta línea la incidencia del Derecho Comunitario. Como me gusta destacar ${ }^{15}$, a diferencia de lo que sucedía en los inicios, desde hace un cierto tiempo el derecho de la Comunidad Europea está salpicado de reglas que tienen que ver con los derechos humanos resultando paradigmático el tan decisivo artículo 6 (en la numeración actual) del Tratado de la Unión Europea, aprobado en Maastricht en 1992. Es este un tema muy rico, sobre el que no voy a insistir ahora, una vez que he dejado constancia del mismo. Pero no puedo por menos de aludir a lo que representa la Carta de los Derechos Fundamentales de la Unión Europea, ahora además con el dato añadido de constatarse formalmente el deseo de consagrar su más plena efectividad jurídica -al margen de la que ya tuviera ${ }^{16}$-, tras la Convención de Bruselas culminada en 2003. No me detendré ahora en destacar los méritos de la Carta, donde junto a una reafirmación y codificación del acervo ya existente, haciendo ostensibles los derechos antes dispersos ${ }^{17}$, se aprovecha, obviamente, para incorporar aspiraciones nuevas, como, por ejemplo, en el campo de la medicina y la biología (art. 3.2), o en el de la protección de datos de carácter personal (art. 8).

c) Si los dos anteriores son los supuestos más institucionalizados, o más ostensibles acaso, quiero dejar constancia, aunque excusaré ahora de dar detalles innecesarios para quien maneja habitualmente el "Boletín Oficial del Estado", de que hay un goteo ininterrumpido de elaboración e incorporación al derecho interno español de valiosísimos instrumentos internacionales.

d) De modo que, a través de unas fórmulas u otras, este paraguas internacional servirá para proteger en el ámbito interno muy cualificados valores. Lo concretaré con un ejemplo clave recalando en un pasaje que me llama la atención en la historia de las Constituciones españolas. A diferencia de lo que ha sucedido en otros países -como Estados Unidos, México, etc.-, por más que fue un tema sangrante entre nosotros, y objeto de muy vivas controversias, ninguno de nuestros textos constitucionales incorporó el mandato, o el simple reconocimiento, de la abolición de la esclavitud, realidad que permaneció en algunos de nuestros territorios hasta hace poco más de cien años. Y que, a pesar de las apariencias, no es sólo un problema del pasado: la variada realidad española, en la que la picaresca no es solo un argumento de las novelas del dieciséis o del diecisiete, nos sorprende de vez en cuando con experiencias patéticas en grado sumo. Es verdad que hoy, con el texto de la Constitución en la mano, hay cláusulas de tanta fuerza, como la afirmación de la dignidad de la persona (art. 10.1), o la proclamación de la libertad (arts. 1.1 y 17), que sirven -o deberían servir- para enervar cualquier variante o modalidad de esclavitud. Pero además de eso, la

\footnotetext{
${ }^{14}$ Puede consultarse en Luis MARTÍN REBOLLO, Leyes Administrativas, 7 a ed., Aranzadi, 2001, 1318.

15 Véase así mi trabajo, Para una afirmación de los derechos fundamentales en la Unión Europea, "Revista del Poder Judicial”, núm. 57 (2000), 36 ss.

${ }^{16}$ Puede consultarse mi trabajo, La eficacia de la Carta, en "Azpilcueta. Cuadernos de Derecho", núm. 17 (2001), 19 ss.

${ }^{17}$ Tal era, como se recordará una de las líneas de insistencia del Informe Simitis, el documento Afirmación de los derechos fundamentales en la Unión Europea. Ha llegado el momento de actuar, elaborado por el "Grupo de expertos sobre derechos fundamentales", en el seno de la Comisión Europea, en 1999. Puede verse especialmente la conclusión tercera.
} 
prohibición expresa de la esclavitud ha pasado a incorporarse a nuestro derecho positivo a través de los mecanismos jurídicos a que vengo refiriéndome. Proclamada de forma enérgica en el CEDH, art. 4.1, a través de ese mandato penetra de forma directa en el Derecho español la regla de que "Nadie podrá ser sometido a esclavitud o servidumbre". De ahí, pasa directamente a la Carta, cuyo artículo 5.1 repite literalmente las mismas palabras. Y al margen de ello, por vía de las convenciones singulares España ha revalido compromisos similares, como los derivados de la "Convención sobre la esclavitud" (BOE de 4 de enero de 1977) o los referidos a la "trata" de personas.

e) Ello me lleva a recalcar de nuevo una idea que juzgo del mayor interés, con la que querría rematar este apartado. Nadie discutiría que la Constitución no soporta que a través de los instrumentos internacionales se introduzcan restricciones en el campo de los derechos fundamentales garantizados. Todos recordamos episodios de algunos países europeos, como Italia y Alemania, en relación con la incidencia del Derecho comunitarios sobre su derecho interno y, en concreto, sobre su Constitución. De ahí la importancia de que la Unión Europea llegara a incorporar en su seno un núcleo consistente en materia de derechos humanos. En el caso concreto de España, aparte de otros argumentos, han de surtir sus efectos las reglas que garantizan la prevalencia de la Constitución como norma, de entre las que resulta determinante la opción a que emplaza el artículo 95: o se renuncia al tratado, o se reforma la Constitución. Por el contrario, en sentido inverso, entiendo que la Constitución, en principio, sí tolera que por la vía de los tratados se incremente el nivel o el caudal de los derechos fundamentales que habrán de quedar garantizados. Digo "en principio", dado que a veces los derechos fundamentales, o algunas de sus opciones, pueden ser de efecto ambivalente, de modo que lo que para algunos sea incremento o ampliación añada, en cambio, restricción para otros. Habrá que estar, por eso al caso. Pero, en principio, insisto, nada impide proyectar los efectos positivos, completando así el ordenamiento jurídico. Entiendo que el texto constitucional, desde esta perspectiva, no es un texto completo y excluyente, no se ha querido que fuera así. Para eso están, precisamente, como ya dije, las ventanas abiertas, como las de los artículos 96.1, e, incluso, 93, que tanto juego pueden dar y, de hecho, están dando, aunque sin olvidar que no todo cabe y que hay que contar siempre con el sistema de límites y contenciones inherente.

Tres. La observación de la experiencia de estos veinticinco años me lleva a reafirmar con energía la idea - no por todos reconocida o respetada-, de que los derechos fundamentales no son valores absolutos, no son opciones irrefrenables, sino que tienen unos confines y unos límites que los enmarcan y delimitan y que, en ocasiones, implican la introducción de restricciones. Hay que extremar la atención, por tanto, para saber hasta dónde alcanza la virtualidad de cada derecho o libertad. Bastará con referirse a algunos ejemplos de la realidad cotidiana.

a) Por más que la regla sea la contraria, caben las excepciones: en ocasiones se quebranta la intimidad del domicilio y, aún forzando la voluntad del afectado, se autoriza la entrada de agentes públicos, o, sorprendiendo su confianza, se realizan escuchas telefónicas. Ciertamente que los poderes públicos no son libres para las actuaciones de este tipo: la intromisión se tolera porque hay razones superiores y porque 
así lo ha establecido la ley, que impone $\operatorname{condiciones~}^{18}$ y debe contener unos requisitos $\operatorname{claros}^{19}$.

b) Los partidos políticos representan una opción elemental en las sociedades democráticas y habrán de gozar de todas las consideraciones... pero no todo les está permitido ni su reconocimiento es incondicional. No cabe cualquier cosa bajo el pabellón "partido político". Será normal por eso que queden deslegitimados y que sean incluso invalidados si pretenden objetivos incompatibles con el sistema democrático de libertad y participación o si auspician, defienden o practican el uso de medios violentos para la consecución de aquellos. Bien claras, y un serio aviso para algunas prácticas españolas, resultan ser las dos sentencias del Tribunal Europeo de Derechos Humanos en relación con el caso turco del "Partido de la Prosperidad"20.

c) No deberá faltar la mención a la libertad de expresión, uno de los valores consolidados e incuestionables para los sistemas democráticos. Por grande que sea su fuerza, tampoco cabe todo a su amparo. Se ha repetido hasta la saciedad pero no hay que cansarse, por más que sean muchos los recalcitrantes. El sistema europeo en general $\mathrm{y}$, en concreto, el sistema español, nada tienen que ver con el sistema estadounidense, presidido por la impronta de la "Primera Enmienda". Aquí sí que hay límites, lo cual resulta por otra parte positivo y encomiable, dado que se trata de defender valores superiores $^{21}$. Siempre que se respete la ley, no hay por qué acomplejarse de la existencia de posibles restricciones, pues en definitiva el universo de los derechos fundamentales necesita para bien funcionar de un conjunto de contenciones junto a las opciones. Es positivo, repito, que existan unos límites y que se hagan respetar. Se trata sólo de que se cumpla la Constitución - para algunos, es como si no existieran los preceptos que no les convienen, pero ya se sabe que es ley universal la de que los prepotentes clamen por la desaparición de las reglas jurídicas que suelen defender a los más débiles-, y a este respecto se introdujo, ponderando ciencia y experiencia, un mandato de gran saber:

"Estas libertades tienen su límite en el respeto a los derechos reconocidos en este Título, en los preceptos de las leyes que lo desarrollen y, especialmente, en el derecho al honor, a la intimidad, a la propia imagen y a la protección de la juventud y de la infancia”.

Lo anterior no es ningún arcano o ninguna sorpresa, es sólo una parte del importante artículo 20 que consagra las opciones de la libertad de expresión, y que

\footnotetext{
${ }^{18}$ Como que, salvo excepciones, se requiera mandamiento judicial para la entrada en los domicilios.

${ }^{19}$ De recordar así, el rigor exigido por la jurisprudencia del Tribunal Europeo de Derechos Humanos, en el sentido de que la ley que autorice las escuchas telefónicas sea lo suficientemente precisa como para facilitar la previsibilidad por parte del afectado. He abordado este aspecto en mi reciente trabajo, La calidad de la ley según la jurisprudencia del Tribunal Europeo de Derechos Humanos (Especial referencia a los casos "Valenzuela Contreras" y "Prado Bugallo", ambos contra España), en "Derecho Privado y Constitución”, núm. 17 (2003), epígrafes 17 y siguientes.

${ }^{20}$ Véase, así, sobre la primera de ellas, mi trabajo, El problema de las aspiraciones religiosas incompatibles con el sistema democrático. ¿Se justifica la disolución de un partido político que las auspicia? (STEDH "Partido de la Prosperidad y otros c. Turquía", de 31 de julio de 2001), en "Revista Española de Derecho Europeo", núm. 2 (2002), 337 ss.

${ }^{21}$ Para un desarrollo de estas ideas, me remito a mi trabajo, Libertad artística y de expresión y protección de la infancia y juventud, en el libro citado, La Europa de los derechos humanos, 357 ss.
} 
marca el necesario equilibrio dentro del conjunto. Ni que decir tiene que es desarrollo directo de una regla básica en materia de derechos fundamentales, precisamente la que abre el Título Primero, el artículo 10.1, donde se proclama la tónica de "respeto" que debe derivar de la dignidad de la persona.

Insisto que se trata de deducciones jurídicas obvias y elementales, pero a veces no está de más remachar lo claro cuando hay quien se dedica intencionadamente a enturbiar las aguas. ¡Todos los apoyos y respetos para la libertad de expresión! Pero ésta, en ocasiones, habrá de respetar otros derechos. Quien se sitúe al margen de la regla, no puede pretender ser amparado pues la libertad no justifica cualquier cosa. Tal es el régimen jurídico vigente.

d) Con fórmulas como las señaladas, el Derecho español no hace sino seguir el criterio de los modelos más solventes en materia de derechos humanos dentro de nuestro ámbito cultural. En efecto, cualquiera puede saber que la solución referida se halla también consagrada, y de manera reiterada, en el CEDH, que lo tomó a su vez de la Declaración Universal de Derechos Humanos, artículo 29.2. En efecto, el Convenio, como se recordará, en muy cualificados preceptos, incluye un apartado segundo donde se sientan las bases para posibles restricciones, al tratarse, en concreto, del derecho al respeto a la vida privada y familiar (art. 8), a la libertad de conciencia, de pensamiento y de religión (art. 9), a la libertad de expresión (art. 10), a la de reunión y asociación (art. 11 ), etcétera ${ }^{22}$. Y no es ocioso comentar que, en relación con el conjunto de opciones que derivan de la libertad de expresión, el apartado segundo del artículo $10 \mathrm{CEDH}$ se inicia con un recordatorio tan oportuno como exigente: "El ejercicio de estas libertades, que entrañan deberes y responsabilidades, podrá ser sometido a ciertas formalidades, condiciones, restricciones o sanciones”, etcétera. ¡No está mal como aviso para navegantes!

Insisto sobre ello porque no es de recibo dejarse seducir por el espejismo de sistemas foráneos, como el estadounidense, cuando Europa cuenta, entre los logros más destacados de su legado histórico, con el destacadísimo elemento de nuestra cultura de los derechos humanos. De la que debemos estar orgullosos, por lo que vale, y, por ende, prestos a defenderla. Y es que es el mejor testimonio de tantos y tan prolongados trabajos y esfuerzos por la implantación de una sociedad moderna y justa, y, por ende, dedicados a la superación del absolutismo, de todo tipo de tiranías, de imposiciones y fundamentalismos religiosos de cualquier especie, o de los totalitarismos.

Cuatro. La idea de límites, confines y restricciones me lleva a insistir para poner el acento en un aspecto muy importante, cuanto obvio y elemental, pero cuya evolución en estos años no resulta nada encomiable, antes bien, da testimonio de una falta de madurez, sobre lo que, además, poco se ha dicho, desde ese complejo de quien tiene las cosas poco claras -o de quien tiene mala conciencia-, y teme que le tilden de poco demócrata. Y, a veces, se deja de ser demócrata no por las carencias sino por las demasías. Lo diré en dos palabras: no es la manera más adecuada de practicar los derechos fundamentales la de perjudicar, molestar o hacer sufrir a los demás. Y es que

\footnotetext{
${ }^{22}$ Criterio que ahora aparece recogido con carácter general en el art. 52.1 de la Carta de la Unión Europea.
} 
se ha instalado en nuestra sociedad la morbosa idea de que para practicar algunos derechos no sólo hay que hacerse notar -lo cual es obvio y sí forma parte del contenido del derecho-, sino que, por añadidura, hay que ocasionar perjuicios y, tal vez, sufrimiento, no ya a algún destinatario concreto, causante o responsable de la injusticia que se reprocha, sino de forma indiscriminada y toque a quien toque ${ }^{23}$, como si todo estuviera presidido por una perversa deformación del conocido consejo evangélico, que quedaría en cambio en un "imolestaos los unos a los otros!”.

Acabo de referirme a la idea de respeto a los derechos de los demás, que conlleva los consiguientes límites, que tan claramente luce en preceptos decisivos de nuestro ordenamiento jurídico, como los artículos 10.1, ó, 20.4, de la Constitución, en los citados preceptos del CEDH -o en el artículo 52.1 de la Carta, en la medida en que sea aplicable-. Lo cual no es nada nuevo, por otra parte, sino que se sitúa en la más genuina tradición del Estado constitucional, que tiene una preclara representación en el artículo 4 de la Declaración de Derechos del Hombre y del Ciudadano de 1789,

"El ejercicio de la libertad consiste en hacer todo aquello que no perjudique a otro: por eso, el ejercicio de los derechos naturales de cada hombre no tiene otros límites que los que garantizan a los demás miembros de la sociedad el goce de estos mismos derechos. Tales límites sólo pueden ser determinados por la ley".

Viejo precepto, tan cálido y certero, hoy reverdecido y rescatado para el ordenamiento jurídico, en cuanto forma parte ya sea del "bloque de la constitucionalidad" en Francia, ya sea, como me gusta destacar, de las "tradiciones constitucionales comunes" a los Estados miembros de la Unión Europea.

Tónica de respeto a "el otro", ya desde los orígenes, y hoy imprescindible. No se justifica, por eso, la pulsión absoluta de los derechos, el obrar sin miramientos, el no tomar en consideración los perjuicios ajenos. Cualquiera conocerá cientos de ejemplos de la vida cotidiana española. No me resisto por eso a consignar algunos ejemplos.

a) No es correcto ejercer el derecho de manifestación interrumpiendo el tráfico por la carretera, por la autovía o por el ferrocarril.

b) Es terrible que maten a un taxista, pero no por ello están legitimados sus compañeros para colapsar el tráfico y paralizar toda la ciudad.

c) No es correcto impedir, "chafar" o "reventar", el mitin, la manifestación o el acto de culto de los demás. Con frecuencia, los periodistas jalean a los "reventadores" y celebran y sonrían "sus gracias", sobre todo si afectan a conocidos líderes, pero cualquiera sabe que según los cánones democráticos, son actuaciones que no tienen legitimación alguna.

Diría más aún. Forma parte del derecho de reunión o del de manifestación el ser respetado, incluso, el ser dejado solo. Nada impide que, dentro de la ley, uno manifieste las ideas que quiera, pero es necesario que se produzca un reparto de los espacios y de los tiempos. No caben interferencias. No es legítimo, en absoluto, por tanto, que se

\footnotetext{
${ }^{23}$ Con la paradójica situación de que casi siempre, si es que puede utilizarse la expresión, "pagarán justos por pecadores".
} 
sitúen inmediatamente al lado de quienes hacen público un sentimiento, los que, defendiendo lo contrario, están, de hecho, por activa o por pasiva, coartando o increpando a los contrarios. En democracia, el derecho de manifestación no tiene por qué ser un acto de heroísmo. Alguien tiene que amparar y tutelar la normalidad. Insisto en que es decisivo un reparto del tiempo y, en su caso, del espacio. No habrá que prohibir la "contramanifestación", pero sí situarla en otro lugar o a otra hora. Del mismo modo que los manifestantes no pueden pretender ocupar la "plaza del pueblo" o la "plaza mayor", el día de la fiesta, cuando ahí se reúnen habitualmente los ciudadanos en torno a los danzantes, al concierto, al pregón, al desfile cívico, a los gigantes y cabezudos, a la procesión o a la misa, o a cualquiera de las variantes que ofrece la rica realidad social española ${ }^{24}$.

d) El espacio tiene muchos significados en la vida social y urbana. Por ejemplo, los representantes populares han querido, y así lo han manifestado en la ley -siguiendo una arraigada tradición democrática- que no se celebren manifestaciones en las proximidades del Parlamento, como ha estudiado recientemente el profesor Sáinz Moreno $^{25}$. El significado del Parlamento en el Estado democrático tiene unas connotaciones que hay que respetar, de muy diversas maneras. Los símbolos son los símbolos y merecen un trato deferente. Pues bien, no se entiende en democracia, el juego rupturista, incluso de partidos y de fuerzas genuinamente democráticos, que no tienen otro afán que ir a celebrar su manifestación en el ámbito que se ha querido reservar a lo parlamentario.

e) Con la importancia que tiene la libertad de expresión o de creación artística no es justificable que se manifieste haciendo pintadas en los edificios o construcciones ajenos, embadurnando incluso con frecuencia lo que son piedras venerables. Se trata de una moda infecta y deleznable que no se entiende por qué goza de amplia tolerancia en algunas ciudades. Insisto, que el que quiera pintar que pinte, pero sin molestar a los demás. Incluso, desde el punto de vista de las ideas políticas, una cosa es pegar carteles, que no deterioran los edificios, y otra muy distinta el borrón de las pintadas. El respeto del patrimonio histórico, del importante valor del ornato ciudadano -la emulación así para que los edificios estén bien pintados o los comercios limpios y preparados-, e, incluso, del derecho de propiedad, introducen aquí limitaciones frente a cuyo desconocimiento habría que ser beligerante. Aunque sólo sea proyectando los gastos de la reparación y una cierta "pecunia doloris" para desaconsejar conductas tales.

f) Una última muestra para cuando declina el día. Salvo para el "patrón”, la fiesta y cuatro fechas señaladas más, no es correcto organizar las diversiones desconociendo la ordenanza municipal y los preceptos legales correspondientes que regulan el respeto cívico y, en concreto, los niveles de ruido. No se entiende en absoluto la tolerancia que practican algunas autoridades, haciendo gala de sus carencias democráticas.

Porque, habrá que decir con énfasis, la democracia es un sistema de contenciones y de respetos. No cabe la pulsión absoluta en el ejercicio de un derecho ni hay espacio para la práctica española tan genuina de la "real gana". Son los antidemócratas los que

\footnotetext{
${ }^{24}$ Por supuesto que ofrezco una emuneración bien contenida porque, con o sin fiestas, todos tenemos en mente cientos de supuestos similares.

${ }_{25}$ Fernando SÁINZ MORENO, Reuniones y manifestaciones ante la sede de los parlamentos, "Cuadernos de Derecho Público", núm. 15 (2002).
} 
auspician demagógicamente y revistiéndose de falsas vestiduras el prescindir del respeto a las barreras indeclinables. No todo está permitido, no todo está permitido en cualquier momento, no todo está permitido en cualquier lugar. La democracia hay que aprenderla y ya se sabe que todo aprendizaje es costoso. Pero vamos, veinticinco años ya son unos cuantos años.

Cinco. Resulta muy interesante en estos años observar el proceso de proyección de contenidos que ha funcionado con largueza. Se trata de un fenómeno relativamente frecuente en la vida jurídica, que se ha activado también al interpretar los preceptos constitucionales sobre derechos humanos. Consiste, en definitiva, en que a un mismo texto se le van encontrando nuevos contenidos. La adaptación a la realidad social suele contribuir, en efecto, a este positivo fenómeno de alargamiento, acaso insensible en el día a día pero que llama la atención cuando se contempla un cierto lapso temporal. Pondré tres únicos ejemplos que ilustran bien la afirmación que desarrollo.

a) Creo que nadie imaginaría cuando se redactó el artículo 18 que la protección de la inviolabilidad del domicilio y de la intimidad llegaría a ser un argumento decisivo a la hora de protegerse contra el ruido. Hoy es algo incuestionable, como he recalcado en varias ocasiones, que, una vez que abrió brecha el Tribunal Europeo de Derechos Humanos -al interpretar el artículo $8 \mathrm{CEDH}$, que equivale a nuestro 18-, se refleja con normalidad en la jurisprudencia contencioso-administrativa, en la civil o, incluso, recientemente, en la penal, aparte de en la del Tribunal Constitucional.

b) Siguiendo también la tónica del Tribunal de Estrasburgo, muy tempranamente el Tribunal Constitucional proyectó la aplicación de las garantías jurisdiccionales del artículo 24 al ámbito de las sanciones administrativas, en concreto la regla de que nadie debería ser sancionado sin haber sido previamente oído (STC 18/1981, de 8 de junio, en el caso de los sindicalistas de Correos, en Barcelona, con ponencia del profesor GómezFerrer).

c) Ni estaba claro que el derecho a la participación del artículo 23 fuera a proyectarse al campo de la función pública, como luego se ha hecho de manera inequívoca ${ }^{26}$.

Seis. Otra línea de ampliación, muy interesante igualmente, es la que se refiere a los sujetos obligados. El planteamiento histórico originario de los derechos humanos se dirigía frente a los poderes públicos y se construyó pensando en sus agentes. Cuando se auspiciaba que no hubiera censura, o que no hubiera intromisiones en el domicilio, ni detenciones ilegales, se pensaba fundamentalmente en contener a los agentes públicos. Concepción que hoy queda reflejada a las claras en el artículo 53.1, cuando se consigna que los derechos y libertades "vinculan a todos los poderes públicos". Por supuesto que resulta fundamental ese efecto primario y para nada ha perdido su funcionalidad. No se

\footnotetext{
${ }^{26}$ Planteaba el problema en una ponencia de 1981, Carrera administrativa y estatus funcionarial (Principios constitucionales sobre la función pública), recogida en mi libro Bajo el signo de la Constitución, Madrid 1983, 443 ss. En sentido terminante puede verse ahora, Manuel PULIDO QUECEDO, El acceso a los cargos y funciones públicas. Un estudio del artículo 23.2 de la Constitución, Madrid, 1992.
} 
puede bajar la guardia, en absoluto. Pero, sin mengua de lo anterior, se va a producir un notable salto cualitativo. Hizo fortuna la concepción de la Constitución como norma, tan decididamente impulsada por García de Enterría ${ }^{27}$, con la intención de considerarla como algo que obligaba y forzaba a predeterminar las conductas, y conforme arraigaba tal criterio, entre las muchas secuelas que derivarían, había una de especial interés para nuestro razonamiento. La Constitución-norma que vincula y obliga, como cualquier norma -al margen de su carácter reforzado-, va a obligar a todos. También a los ciudadanos, a cualquier ciudadano. Y, de hecho, ya lo indica con claridad el artículo 9.1,

"Los ciudadanos y los poderes públicos están sometidos a la Constitución y al resto del ordenamiento jurídico".

Sometidos todos, tanto los poderes públicos como los ciudadanos, a todo el ordenamiento jurídico, a todo él, también a la Constitución. Es decir, que sus contenidos son normas que obligan: obliga el respeto a la ley, el respeto a las sentencias, el cumplimiento de las cargas tributarias y demás deberes cívicos. Pero, por lo mismo, también obligan los preceptos que sustentan todos y cada uno de los derechos fundamentales. El que los poderes públicos tengan unas cargas especiales no obsta a la situación de obligación de los ciudadanos en aquello que les afecte. Todos y cada uno de los derechos y libertades, o el mandato de la no discriminación, van a traducirse en la necesaria situación de respeto. De modo que el ciudadano, como padre de familia o como miembro de un matrimonio o de una relación de convivencia, como conductor, como trabajador, empleado o funcionario, como empresario, como responsable religioso o como gestor de los servicios público, es decir, en cualquiera de las situaciones de relevancia social, ha de saber que tiene la obligación de respetar los derechos fundamentales y las libertades públicas. Cierto que algunos remedios están pensados para ser aplicados de forma concreta en relación con los poderes públicos, lo que significa que posiblemente no puedan ser aplicables a los ciudadanos en general. No importa. Tal exclusión se referirá a ese remedio concreto, pero no por ello se excepciona la situación general de obligación ni el uso de otros remedios que puedan ser utilizables. Lo explicaré con un ejemplo: el que el "habeas corpus" no resulte obviamente operativo frente a una banda de delincuentes chantajistas por medio del secuestro, no implica que no se puedan utilizar los correspondientes preceptos del Código Penal, ni movilizar a la policía y a la opinión pública, o cualesquiera otros medios legítimos.

Resulta así un aspecto sobresaliente de la teoría de los derechos fundamentales el que pasen a convertirse en elemento decisivo de la convivencia cívica, desde la obligación que tienen todos de respetarlos. Lo que significa que habrá que tener muy presente este carácter dual en cuanto a sus destinatarios: por supuesto y ante todo, los poderes públicos, en cuanto los derechos humanos fueron inventados como barreras y escudos frente a los mismos, pero también, sin falta, esa otra vertiente, tan distinta, que exige hoy el respeto por parte de los ciudadanos. En el complejo mundo de las relaciones sociales, la veta de autoorganización de cada persona habrá de contar necesariamente con esta barrera de respeto a los derechos fundamentales de los demás. Pero dígase lo mismo en el campo de la producción y en el del comercio y en el del

\footnotetext{
${ }^{27}$ Valga una remisión a su importante libro, La Constitución como norma y el Tribunal Constitucional, ed. Cívitas, primera edición de 1981, con varias ulteriores.
} 
mercado: las relaciones laborales, las relaciones con consumidores y clientes ${ }^{28}$, la mera actividad de publicidad, habrán de partir de la base de que junto a los ámbitos de libertad y libre disposición resulta inexcusable el canon de respeto a los derechos fundamentales de los demás. No es preciso recalcar que se trata de una conclusión con grandes implicaciones, que hacen aún más sugestiva e interesante la teoría de los derechos humanos. Pero por las limitaciones señaladas, no insistiré ahora en esta línea y me limitaré a traer un mero ejemplo.

Quiero poner el acento en un caso significativo, que tiene que ver con los sujetos obligados y que, en línea con lo que antes se señalaba, nos lleva a constatar como se puede utilizar hoy un texto para algo que inicialmente no se había ni sospechado. Tomemos el famoso mandato del artículo 15 de la prohibición de tortura y de penas 0 tratos inhumanos o degradantes. Se imaginaría inicialmente como pensado para proteger frente a lo exterior, frente a lo ajeno: así, que los agentes públicos, ni en las comisarías, ni en las cárceles, ni en los reformatorios, ni en asilos, ni orfelinatos, ni en residencias, ni en cualquier centro de internamiento, ni en los cuarteles, ni en los colegios, etc., incurrieran en tales prácticas. Ahora, sorpresivamente, en vista de las necesidades que hoy afloran de manera tan contundente, se puede proyectar a lo más íntimo, al hogar, a la relación familiar o sentimental. Así, que el varón no se sobrepase con la mujer. Nadie dudará hoy que sea ésta una variante de trato inhumano o degradante, por lo que el artículo 15 puede desempeñar una nueva funcionalidad. No faltaban, obviamente, otros soportes constitucionales, como el derecho a la vida y a la integridad física, del propio precepto. Pero cuando hay que afrontar con energía una necesidad social que se hace apremiante, buenos son todos los apoyos y argumentos.

Siete. Querría decir, aunque sea muy brevemente, que me parece muy de encomiar la fórmula española, por la que intencionadamente apostó la Constitución, que parte de la existencia de graduaciones para la eficacia, defensa y aplicabilidad de los derechos fundamentales, ese sistema de escalonamiento que en otros lugares he estudiado. Es positivo que haya sensibles diferencias entre unos y otros. Sin duda, todos son compromiso directamente derivado de la Ley Fundamental, todos obligan y tornan inconstitucional cualquier conducta que se aparte de los mismos. Pero está muy bien que sea necesaria la intermediación del legislador para unos cuantos casos, lo que el texto denomina los principios rectores de la política social y económica (del Capítulo tercero). Hay una enorme variedad de supuestos y es bien distinta la situación de los afectados; por otra parte, se impone reflejar la evolución de la sociedad con su dinámica, del mismo modo que las exigencias y aspiraciones pueden alterarse, amortiguarse o conocer ritmos intensísimos, y no queda más remedio que optar, seleccionar, concentrar esfuerzos, marcar criterios y requisitos y, en su caso, señalar preferencias. Cada sociedad cuenta con los medios con los que cuenta-aquí se impone el tan certero y clásico adagio de que "no hay más cera que la que arde"-, y a veces se impone marcar tónicas de reparto o, incluso, de primacía (que suelen ser también de selección y, por ende, de exclusión). La ley deberá ser razonable y proporcionada $-\mathrm{y}$

${ }^{28}$ Véase Javier GUILLÉN, El estatuto de los consumidores, Cívitas, Madrid, 2002. 
soportar el test de constitucionalidad ${ }^{29}$-, pero es lógico que sea el legislador quien marque y vaya poniendo al día los criterios para orientar la labor de la Administración al ejecutar. Y en caso de conflicto, diría en este sentido, que comulgo con la idea clásica de que la más honrosa tarea del juez es la de ser un leal aplicador de la ley. El tener que inventar, no es tarea cómoda, ni positiva. No es ninguna antigualla defender el principio de separación y contención de poderes, a que me refería al comienzo. Por más que se manejen cifras millonarias, hoy el funcionamiento del Estado es muy complejo, todo tiene implicaciones financieras y presupuestarias, que son controladas y aprobadas por el Parlamento con la significativa iniciativa del Gobierno. Bien sé que hay casos difíciles y que la realidad de las lagunas de la ley puede colocar en situaciones apremiantes. Aparte de los cada vez menos infrecuentes desfases entre la respuesta legal y la necesidad social. Con todo, insisto en el principio: no es bueno que el juez invente. ¡Afortunado el juez que puede vivir como leal aplicador de la ley!

Desde otra perspectiva me parece positiva la graduación entre los derechos fundamentales propia del sistema español: es lógico que no llegue al Tribunal Constitucional cualquier cosa. El recurso de amparo, como tantas veces se ha dicho -al parecer, en vano-, sólo debería ser un remedio excepcional, resultando suficiente con la garantía judicial. Entiendo que los abogados querrían siempre más oportunidades, pero a mí me parece correcto que haya unas reglas de juego claras, con la consiguiente selección. Para que el sistema funcione se requiere una cierta celeridad y no queda más remedio que defenderse frente a la sobrecarga de papel.

Todo lleva a recalcar la mayor profesionalidad posible para el escalón judicial, el esfuerzo por la facilitación de una realidad jurídica tan compleja, así como la necesidad de claridad de reglas. Poco será todo lo que se haga por interesar, y celebro mucho la oportunidad de poder estar esta mañana con ustedes para debatir de estos problemas. Acaso se eche en falta también, en lo que a los profesores respecta, una labor sistemática de comentario y crítica de la jurisprudencia, pausada y objetiva, cubriendo amplias series, y no el tan frecuente estudio del caso interesado, o el centrado en los supuestos más morbosos o aparatosos.

Por unas razones y otras, entiendo -y bien se que no faltan voces que querrían mezclarlo y revolverlo todo- que la fórmula de graduación que inventó la Constitución es $-\mathrm{y}$ ha resultado- pragmática y realista.

Ocho. Se hablaba antes de los derechos fundamentales como ingrediente de la convivencia ciudadana, todos obligados a su respeto, todos vinculados por ellos. Hay por eso una vertiente en la consideración de los derechos fundamentales sobre la que me gusta insistir en cuanto puedo y a la que voy a dedicar ahora los últimos minutos de mi intervención. Empalmamos con la vieja lección histórica de lo importante que resulta que las grandes opciones humanas comiencen a ser inculcadas en la escuela. Los grandes retos de la vida tienen mucho avanzado si hallan un lugar cuándo y dónde se

\footnotetext{
${ }^{29}$ Quedando sometida, por ende a los correspondientes controles del Tribunal Constitucional, sin excluir, cuando proceda, el control de la inactividad del legislador, en la línea desarrollada por Marcos GÓMEZ PUENTE, La inactividad del legislador: una realidad susceptible de control, Ed. Mc Graw-Hill, Madrid, 1997
} 
practica la enseñanza. Y me da la impresión de que en este punto la evolución de los veinticinco años deja mucho que desear. Ojalá se tome nota de ello y sea preocupación que aflore con motivo de las celebraciones de los veinticinco años.

Por otra parte, esta preocupación por la vertiente didáctica de los derechos fundamentales ha sido casi connatural a la evolución de los mismos. No es cuestión de hacer historia ahora, pero sí quiero refrescar un par de datos. Sobresaliente me parece el ejemplo de la Declaración Universal de Derechos Humanos, en la Proclamación que se incluye dentro del Preámbulo, donde se aludirá al,

“...ideal común por el que todos los pueblos y naciones deben esforzarse, a fin de que tanto los individuos como las instituciones, inspirándose constantemente en ella, promuevan, mediante la enseñanza y la educación, el respeto a estos derechos y libertades...".

El mensaje resulta inequívoco y no deja lugar a dudas. La solemnidad del documento se vuelca también para reclamar la promoción mediante la enseñanza y la educación. Late, en el fondo, la vieja y sabia filosofía de que no basta con legislar, o con elaborar un texto, como en el caso, sino que lo esencial es propagar los contenidos entre los ciudadanos afectados, y nada más propio que resaltar la conveniencia de la labor docente.

Pero no es sólo cuestión del Preámbulo. Una de las preocupaciones más legítimas de la Declaración es la de generalizar la educación, a todos los niveles, auspiciando que sea gratuita en el nivel elemental. A ello se dedica un importante precepto, el artículo 26. Pues bien, no es sólo la tónica generalizadora, no basta con proclamar el derecho a la enseñanza. Se parte de que ésta debe tener contenidos imprescindibles cuyo sentido se quiere marcar. Es así como nos encontramos con el apartado segundo del señalado precepto, muy rico en sustancia, cuyo alcance debe ser recordado:

"La educación tendrá por objeto el pleno desarrollo de la personalidad humana y el fortalecimiento del respeto a los derechos humanos y a las libertades fundamentales; favorecerá la comprensión, la tolerancia y la amistad entre todas las naciones y todos los grupos étnicos y religiosos; y promoverá el desarrollo de las actividades de las Naciones Unidas para el mantenimiento de la paz".

Es un mensaje -o, mejor, un mandato- de enorme potencia y de alta calidad humana, que no ha perdido ni un ápice de su fuerza en los años transcurridos. Antes bien, ha servido de ejemplo y ha ido inspirando, como inmediatamente expondré, muy preclaros documentos. Pero la lección a extraer ahora es que junto a la generalización de la enseñanza, que representa la consagración del derecho a la educación, llave certera e inexcusable para superar el atraso y la pobreza, el respeto a los derechos humanos debe ser algo propagado y generalizado ya desde la escuela, en unas y otras latitudes. Educar es, junto a la impartición de los saberes usuales, también la enseñanza del respeto a los derechos humanos.

Quede así este pequeño apunte extraído de uno de los grandes documentos del Siglo XX. Que tendría influencia señera, como dije. En efecto, salto ahora al precepto que la Constitución Española dedicó al tema de la educación que, como se verá, denota la influencia directa de la Declaración Universal. Advierto que se trata de un precepto 
-el artículo 27- medido y aquilatado hasta el milímetro, fruto granado del "consenso", en tema de capital importancia y con visiones tan enfrentadas. Pues bien, una vez que en el apartado primero se ha reconocido el derecho a la educación, en el segundo se precisará:

"La educación tendrá por objeto el pleno desarrollo de la personalidad humana en el respeto a los principios democráticos de convivencia y a los derechos y libertades fundamentales".

Es decir, fuerza y significado de la educación, pero esta debe incluir necesariamente el aprendizaje en el respeto a los derechos y libertades fundamentales.

Entiendo que se trata de un reto mayúsculo, por más que sea aplicación de la pura letra de la Constitución que tanto se celebra. No es correcto ensalzarla en su conjunto, quedarse en la visión global y pasar por encima de exigencias tan precisas y tan ricas en consecuencias como ésta. ¿Creen ustedes que tan importante previsión se cumple y respeta en todo el territorio nacional? Espero que convendrán conmigo en que es mucho lo que queda por hacer en este terreno. La evolución durante los veinticinco años no ha dado ni con mucho el juego que cabía esperar. Porque además era imaginable una emulación de las Comunidades Autónomas, con tan amplias competencias en materia educativa, cuando incluso todos los Estatutos de Autonomía tienen un precepto similar que recuerda que los ciudadanos de cada una de ella tienen los derechos (y deberes) fundamentales que enumera la Constitución. Uno de los cuales, y sobresaliente, es el del artículo 27.

Entiendo que es éste un problema de primordial interés, de esos que justificaría un amplio debate nacional, una movilización seria de la opinión pública. Pero no pocos líderes políticos no están por la labor. Les debe parecer más rentable la continua huida hacia delante, encubriendo sus limitaciones o falta de proyecto sugestivo, con el movimiento continuo de la reforma estatutaria, o constitucional, si les da por eso. Creen aparentar con ello una grandeza, que no hace más que tapar pequeñas miserias. La profundización en los derechos fundamentales, sí es un solvente programa de futuro. Ojalá no se malbarate tan importante ocasión.

\section{FINAL}

Voy a terminar ya. Me agrada esta oportunidad de haber reflexionado ante ustedes sobre la Constitución Española, sus primeros veinticinco años, y uno de sus contenidos más valioso y delicado, los derechos fundamentales. Se trató de su recepción y del desarrollo ulterior, pero hay que ser bien conscientes de que estamos ante un proceso incesante que nunca puede detenerse. Está, ante todo, el empeño de profundización de lo ya proclamado, el que la letra de la ley penetre inequívocamente en los usos sociales. A su vez, la propagación de las fórmulas, el gran reto de nuestra época de la promoción de la igualdad: cada vez se justifican menos los oasis florecientes pero aislados en un mundo como el nuestro, auténtico pañuelo. Pero también la seguridad de que cuando el actual nivel arraigue, se afiance y se propague, surgirán nuevas aspiraciones y emergerán nuevas pretensiones que probablemente adopten la veste de derechos 
fundamentales. Acaso haya entonces que ajustar la Constitución, bien directamente actuando sobre su texto, bien a través de fórmulas complementarias, alguna de las cuales quedó fielmente reflejada.

De todas maneras, en el actual panorama, es mucho lo que queda por hacer. Es preciso no ser triunfalistas, pero sí constantes y firmes. Y conviene sobre todo no trivializar el rico y trascendente caudal de los derechos humanos, no malbaratar su energía con banalidades, no usarlos para cualquier cosa. Porque cada Declaración de Derechos, cada uno de sus contenidos, tiene algo de ese mundo fascinante de los espirituales negros, tiene mucho de cántico de afirmación y de esperanza, pero ofrece también en el recuerdo la inevitable presencia del dolor, del sufrimiento y de la humillación que se trata de superar ${ }^{30}$.

${ }^{30}$ El presente trabajo se concluyó en Redes (La Coruña), el 10 de agosto de 2003. Se enmarca en el Proyecto BJU 2001-1929, del Ministerio de Ciencia y Tecnología, sobre "Garantía y protección de los ciudadanos...", del que yo mismo soy director. 